\title{
Perioperative glucocorticoid stress dosing: a survey of anesthesiologists and general internists
}

\author{
Catherine Groleau, MD • Michael J. Wong, MD (D) Orlando Hung, MD • \\ Suzanne N. Morin, MD, MSc $\cdot$ Line Vautour, MD $\cdot$ Amal Bessissow, MD, MSc
}

Received: 26 May 2018/Revised: 11 August 2018/Accepted: 13 August 2018/Published online: 7 September 2018

(c) Canadian Anesthesiologists' Society 2018

\section{To the Editor,}

Perioperative glucocorticoid (GC) stress dosing has long been recommended for patients with significant preoperative exogenous GC exposure, but remains controversial because of a lack of high-level evidence to support it. ${ }^{1,2}$ In this context, we sought to characterize perioperative GC stress dosing patterns among Canadian physicians, specifically anesthesiologists (ANs), general internists (GIMs), and endocrinologists (ENs).

Following institutional ethical approval, we invited physician members of the Canadian Anesthesiologists' Society (CAS), Canadian Society of Internal Medicine (CSIM), Association des Spécialistes en Médecine Interne du Québec (ASMIQ), and Canadian Society of

Electronic supplementary material The online version of this article (https://doi.org/10.1007/s12630-018-1219-7) contains supplementary material, which is available to authorized users.

C. Groleau, MD

Hematology Residency Program, McGill University, Montreal, QC, Canada

M. J. Wong, MD

Anesthesiology Residency Program, Dalhousie University, Halifax, NS, Canada

\section{O. Hung, MD}

Department of Anesthesia, Pain Management \& Perioperative Medicine, Dalhousie University, Halifax, NS, Canada

S. N. Morin, MD, MSc · A. Bessissow, MD, MSc ( $\square)$ Division of General Internal Medicine, Department of Medicine, McGill University Health Centre, Montreal, QC, Canada e-mail: amal.bessissow@mcgill.ca

L. Vautour, MD

Division of Endocrinology, Department of Medicine, McGill University Health Centre, Montreal, QC, Canada
Endocrinology and Metabolism to participate in a 19item online survey (Appendix 1, available as Electronic Supplementary Material [ESM]) from March to July 2017. One thousand seven hundred seventy-four CAS members and $856 \mathrm{CSIM} / \mathrm{ASMIQ}$ members were invited to participate, with 447 (17\%) surveys completed (ANs, $n=$ 295; GIMs, $n=145$; ENs, $n=7$ ). Due to the few EN responses received, these data were excluded from analysis. Most respondents worked at an academic centre (ANs, 62\%; GIMs, 58\%). Respondents practiced in all regions of Canada, though GIMs were predominantly from Ontario and Quebec (94\%). For further details, refer to ESM Appendix 2.

In terms of preoperative evaluation, 173 respondents (39\%) felt extremely or very confident in their ability to choose an appropriate stress dose regimen (ANs, $n=90$, 31\%; GIMs, $n=83,58 \%$ ). Three hundred fifty-six respondents $(81 \%)$ agreed or strongly agreed that guidelines for perioperative $\mathrm{GC}$ administration are needed (ANs, $n=240,82 \%$; GIMs, $n=116,80 \%$ ). Respondents judged patients to be at higher risk for adrenal insufficiency when taking higher preoperative oral prednisone doses for at least three weeks in the last year (7.5 mg: ANs, $n=116$, 39\%, and GIMs, $n=87,60 \%$; $10 \mathrm{mg}$ : ANs, $n=177,60 \%$, and GIMs, $n=98,68 \%$; $15 \mathrm{mg}$ : ANs, $n=192,65 \%$, and GIMs, $n=114,79 \%$ ). Most respondents do not preoperatively test for hypothalamic-pituitary-adrenal axis function (ANs, $n=255,86 \%$; GIMs, $n=86,59 \%$ ).

Respondents were presented with five clinical cases and prompted to select their preferred management strategy (Table). Consistent with contemporary stress dosing recommendations, respondents attempted to stratify their GC management regimens based on the perceived likelihood of perioperative adrenal insufficiency. ${ }^{3}$ Respondents provided supplemental GC in two high-risk 


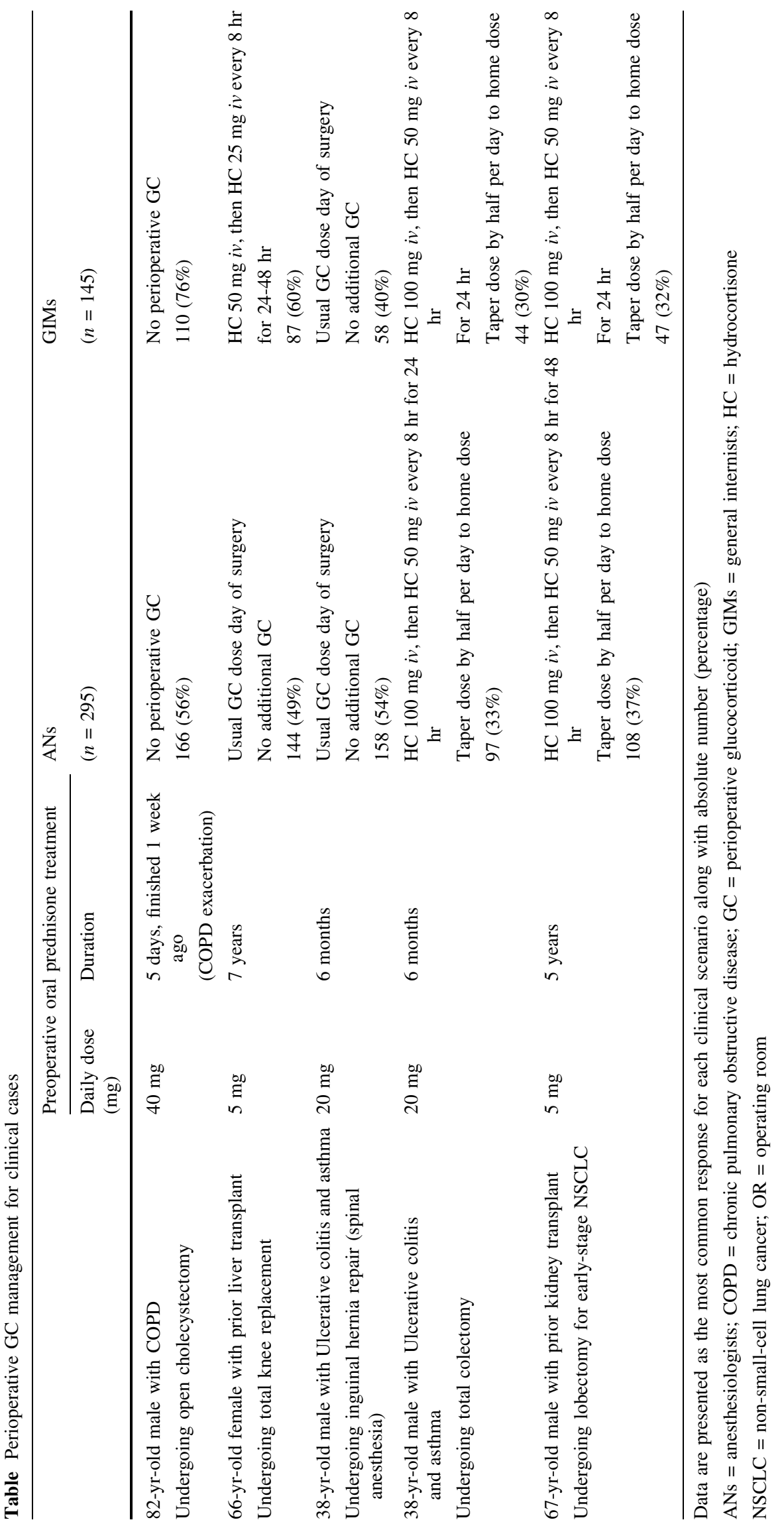


cases and did not give supplemental GC in one low-risk case. For two intermediate-risk cases, there was disagreement on GC management. There was also no clear consensus on the specific stress dose regimen in cases where GC supplementation was favoured.

Interestingly, in each clinical case there was a minority of AN respondents (2-3\%) who specifically recommended dexamethasone as their supplemental GC of choice at doses usually used for postoperative nausea and vomiting prophylaxis (i.e., 4-8 $\mathrm{mg}$ ). This approach is rarely described despite dexamethasone's favourable clinical properties (e.g., lack of mineralocorticoid effect and long duration) ${ }^{4}$

As is generally the case with surveys, this study was limited by a low response rate. Our survey had a reasonable distribution of practice type and years of experience. There was, however, some geographical overrepresentation from Ontario and Quebec, particularly among GIM respondents. Also, their negligible response rate precluded EN input, which could have been very informative. Nonetheless, this is the first interdisciplinary survey of Canadian GC stress dosing practice patterns. The responses illustrated that perioperative GC management remains contentious, especially for intermediate-risk cases. While the degree of confidence around stress dosing was lower among ANs, both specialties expressed a desire for further guidance.
These results support the need for continued clinical research in this field.

Conflicts of interest None declared.

Editorial responsibility This submission was handled by Dr. Hilary P. Grocott, Editor-in-Chief, Canadian Journal of Anesthesia.

Funding Dalhousie University: Department of Anesthesiology, Pain Management \& Perioperative Medicine internal grant.

\section{References}

1. Groleau C, Morin SN, Vautour L, Amar-Zifkin A, Bessissow A. Perioperative corticosteroid administration: a systematic review and descriptive analysis. Perioper Med (Lond) 2018; 7: 10.

2. Nguyen GC, Elnahas A, Jackson TD. The impact of preoperative steroid use on short-term outcomes following surgery for inflammatory bowel disease. J Crohns Colitis 2014; 8: 1661-7.

3. Liu MM, Reidy AB, Saatee S, Collard CD. Perioperative steroid management: approaches based on current evidence. Anesthesiology 2017; 127: 166-72.

4. Wax $D B$. One size fits all for stress-dose steroids. Anesthesiology 2018; 128: 680-1. 